\title{
SYSTEMIC AND RENAL CIRCULATORY CHANGES FOLLOWING THE ADMINISTRATION OF ADRENIN, EPHEDRINE, AND PAREDRINOL TO NORMAL MAN
}

\author{
By HILMERT A. RANGES AND STANLEY E. BRADLEY 1 \\ (From the Departments of Medicine and Physiology, New York University College of Medicine, \\ and the Third (New York University') Medical Division of Bellevue \\ Hospital, New York City)
}

(Received for publication March 10, 1943)

This report concerns the systemic and renal circulatory changes in normal man during the action of adrenin, ephedrine, and paredrinol. Special attention has been paid to the interrelationship and integration of the many factors involved in the production of the over-all response. Although these three substances are similar chemically and have long been known (1) as vasopressor drugs, their sites and modes of action appear to vary. The observations presented here throw light upon the circulatory mechanisms involved in the pressor response.

The subjects were male convalescent patients on the Third (New York University) Medical Division of Bellevue Hospital, who were examined, for the most part, under basal conditions. Adrenin was administered subcutaneously and intramuscularly in 0.5 to $1.5 \mathrm{mgm}$. doses, ephedrine was given intramuscularly in 50 to $75 \mathrm{mgm}$. doses, and paredrinol was injected intramuscularly in 20 to $30 \mathrm{mgm}$. doses, after control values had been obtained.

Cardiac output was determined by a modification of Starr's ballistocardiograph (2), using the wave area formula advocated by Starr (3). The instrument was calibrated after each study by the method recommended by Starr (4). All figures for stroke volume and cardiac output have been increased by 18.5 per cent because Cournand $e t$ al. (2) have shown the ballistocardiographic output to average 18.5 per cent lower than the value obtained by the direct Fick method in man. Arterial pressure was measured directly in the femoral artery with a Hamilton optical manometer (5) and mean pressure was obtained by planimetric measurement of the area under the pressure pulse curve. The total peripheral vascular resistance was calculated in absolute units by

1 Commonwealth Fund Fellow. the formula derived from Poiseuille's Law (6). Pressure changes in the right auricle were measured with a saline manometer, following catheterization (7) of the right heart with a ureteral catheter. The position of the catheter in each instance was verified by fluoroscopy. The base line from which venous pressure was read was that advocated by Lyons et al. (8), which Richards et al. (9) have recently shown to come closer to the true zero level than any other advocated in the literature. The effective renal plasma flow ( $\mathrm{CD}$ in the figure) was measured as the diodrast clearance (10), and glomerular filtration rate ( $\mathrm{CM}_{\mathrm{M}}$ in the figure), as the inulin or mannitol clearance (11). The filtration fraction (FF in the figure), or the fraction of the plasma flowing through the kidney which is filtered at the glomerulus, is the mannitol/diodrast ratio.

\section{ADRENIN}

Figures 1 and 2 indicate the variability of the response to adrenin. This substance was studied in 9 subjects, in 2 of whom blood pressure was measured sphygmomanometrically and mean pressure calculated as 40 per cent of the pulse pressure plus the diastolic pressure (12). Five of these subjects responded with a marked elevation in arterial pressure, the pulse pressure increasing in all instances. Two of this group showed also a rise in the diastolic pressure; the remainder had falling or stationary diastolic pressure levels. Figure 1 (H. V.) illustrates the response observed in 1 of these 2 subjects. These 2 subjects also responded with a rise in peripheral resistance $(R)$, unlike the other subjects studied. A second group of 4, illustrated by Figure 2 (S. $\mathrm{H}$.), responded with very small changes in blood pressure, usually a slight rise in systolic pressure and unchanged or falling diastolic pressure, al- 


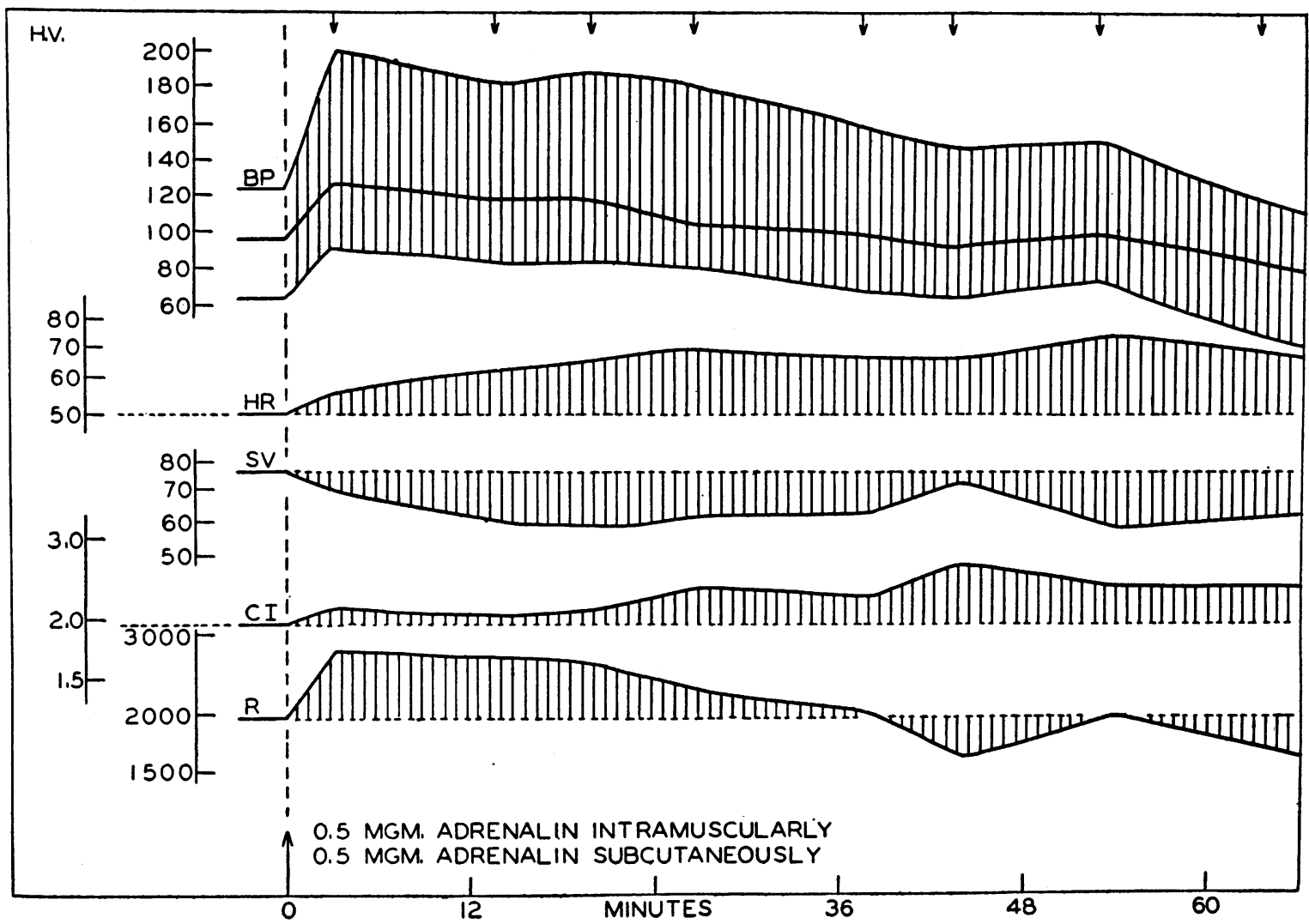

Fig. 1. The Effect of Adrenin on the Circulation in Subject H. V.

$\mathrm{BP}$, blood pressure (Hamilton manometer) in $\mathrm{mm} . \mathrm{Hg}$, the thicker middle line is the mean arterial pressure; HR, heart rate; SV, stroke volume in cc.; CI, cardiac index or cardiac output per square meter of body surface (Ballistocardiograph); $R$, peripheral vascular resistance in dynes $\mathrm{cm}^{-5}$ seconds. The arrows at the top of the figure indicate points at which observations were made.

though similar doses of adrenin were used. The peripheral vascular resistance fell in all these subjects. The cardiac output invariably increased in all subjects, while stroke volume remained unchanged in 5 instances, and on 1 occasion, decreased (Figure 1). On 3 other occasions, the stroke volume increased. Usually a tachycardia resulted, but an abrupt slowing of the pulse rate was observed in 1 instance at the peak of the pressor effect. In 2 additional subjects, the auricular pressure was measured and was found to rise with the blood pressure, rising from +46 $\mathrm{mm}$. saline to $+85 \mathrm{~mm}$. saline in one, and from +58 to +108 in the other. On 2 occasions, renal function was followed and a reduction in renal plasma flow with an increase in the filtration fraction was observed, confirming the findings of Chasis et al. (13).

\section{EPHEDRINE}

The hemodynamic events due to ephedrine were followed in 5 subjects, in 2 of whom the blood pressure was measured sphygmomanometrically and mean pressure calculated as described above. The pressor response to a given dose was always marked and there seemed to be less inconsistency of response than proved to be the case with adrenin. In all subjects, the systolic pressure increased markedly without much change in the diastolic pressure. The cardiac output always increased, although preceded in 1 instance (Figure 3 , A. B.) by a prolonged period (60 minutes) during which there was no change. The stroke volume increased or remained unchanged. No marked changes in pulse rate were observed but a slight increase in rate occurred during the fall of arterial pressure in most subjects. In 1 in- 


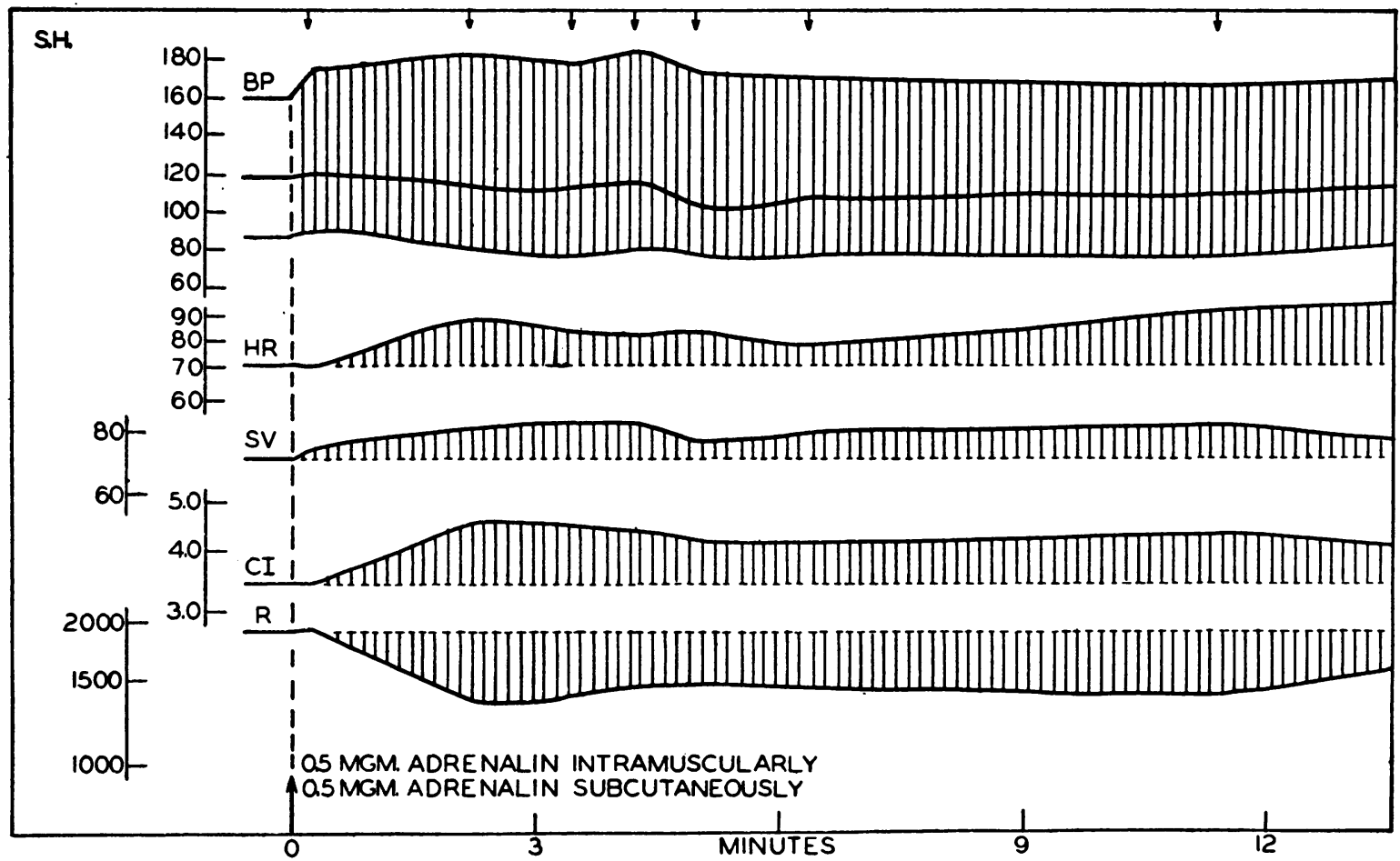

Fig. 2. The Effect of Adrenin on the Circulation in Subject S. H.

Symbols same as in Figure 1.



Fig. 3. The Effect of Ephedrine on the Circulation in Subject A. B.

Symbols same as in Figure 1. AP, right intra-auricular pressure in $\mathrm{mm}$. of saline. 


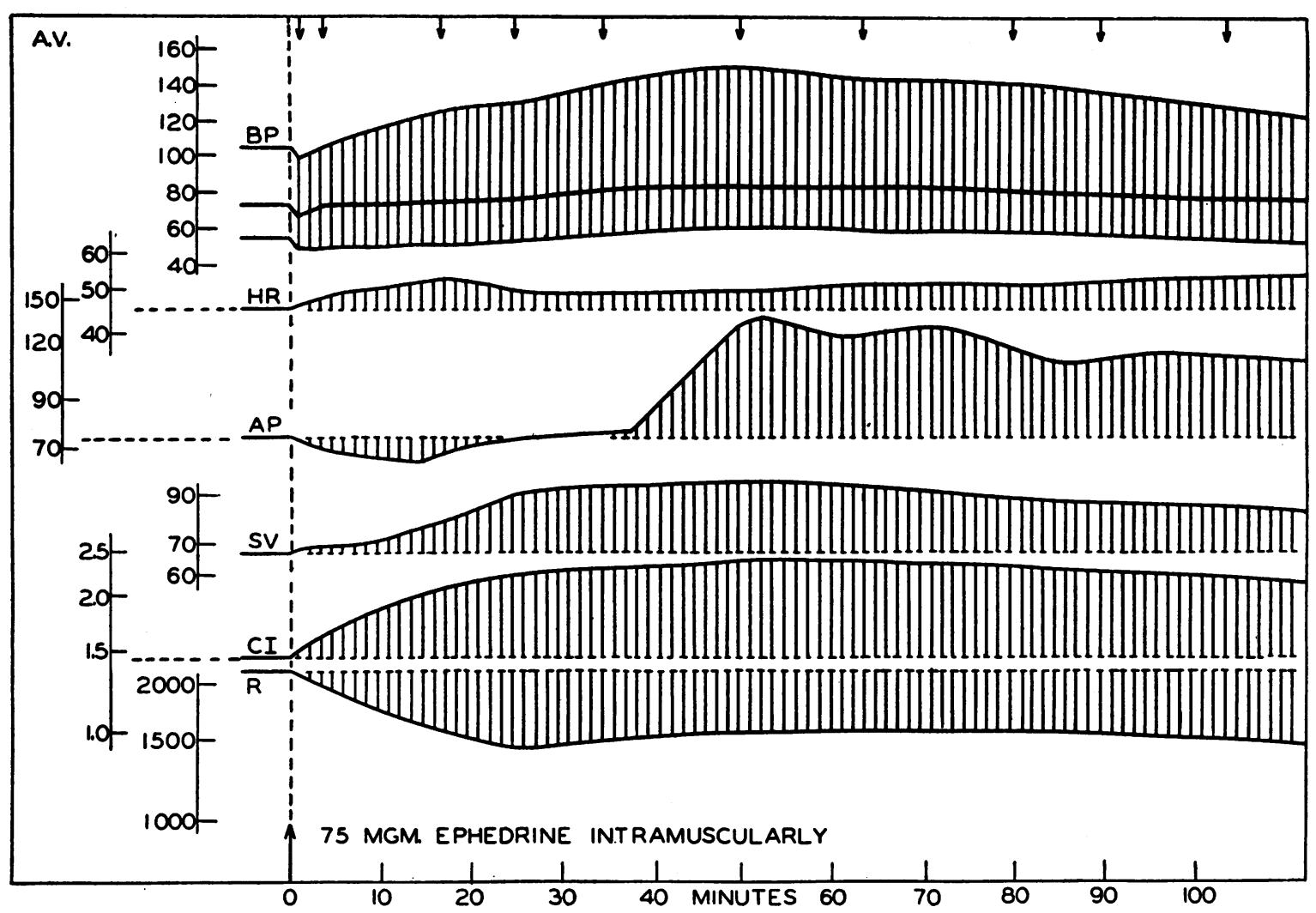

Fig. 4. The Effect of Ephedrine on the Circulation in Subject A. V.

Symbols same as in Figure 3.

stance (Figure 3, A. B.), there was an initial bradycardia. There were no marked changes in the peripheral vascular resistance. The resistance remained unchanged in 3 instances, fell in 1 (Figure 4, A. V.), and rose somewhat in another (Figure 3 , A. B.), although on this occasion, the resistance decreased markedly during the return of the pressure to control levels. Auricular pressure rose in 2 subjects and remained unchanged in a third. The diodrast and mannitol clearances showed the same changes in 6 subjects, following the administration of ephedrine, as those observed following adrenin; viz., a fall in the diodrast clearance without change in the mannitol clearance, and an elevation of the filtration fraction.

\section{PAREDRINOL}

Figure 5 (S. A.) illustrates the representative circulatory changes observed following the intramuscular injection of paredrinol, in a series of 6 studies. The systolic and diastolic pressures increased on every occasion, with widening of the pulse pressure. The heart rate remained unchanged or decreased. With one exception, the output of the heart decreased, while the stroke volume increased on 2 occasions and fell on all others. The peripheral vascular resistance increased markedly in all instances. In the 2 subjects in whom the intra-auricular pressures were measured, this pressure rose well above the control levels shortly after the elevation of the blood pressure. On 4 occasions, the effect of the drug upon renal function was followed. In every instance, there was a reduction in renal plasma flow without a significant change in the glomerular filtration rate. The reduction in the fraction of cardiac output diverted to the kidney during the period of drug action reveals the extent of active renal arteriolar constriction.

\section{DISCUSSION}

Although these substances are very similar chemically, the physiological effects of adrenin and ephedrine stand in striking contrast to those of 


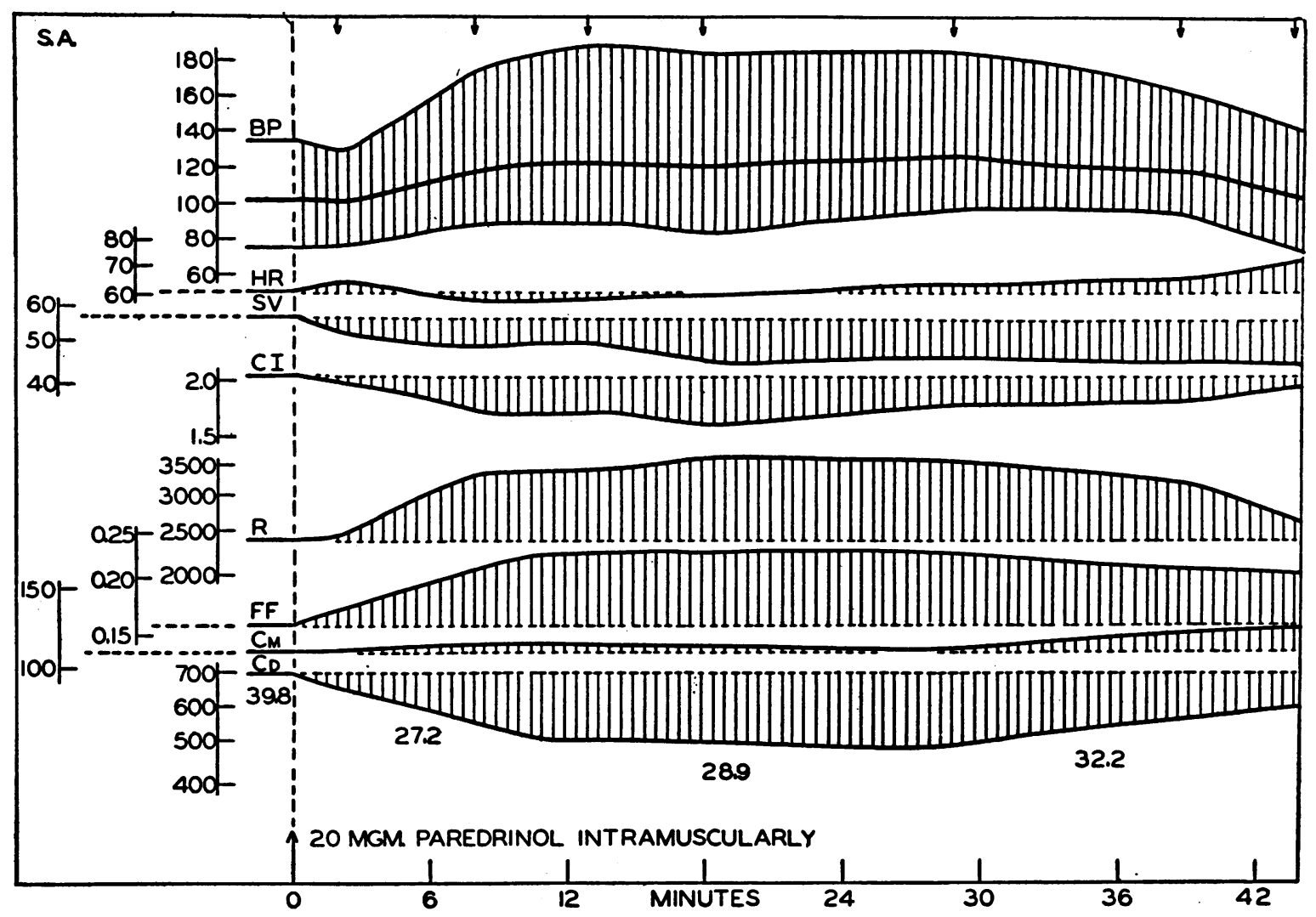

Fic. 5. The Effect of Paredrinol on the Renal Function and Circulation in Subject S. A.

Symbols same as in Figure 1. FF, filtration fraction or fraction of renal plasma flow filtered at the glomerulus; $\mathrm{CM}_{\mathrm{M}}$, mannitol clearance or glomerular filtration rate; $\mathrm{CD}$, diodrast clearance or renal plasma flow. The figures beneath the diodrast clearances are the renal fractions or percentage of cardiac output passing through the kidney.

paredrinol. On the one hand, adrenin and ephedrine show a striking variability of response, while paredrinol proves to have a consistent, predictable action. This lack of physiological similarity indicates different sites and modes of action. The similarity of the action of adrenin and ephedrine supports the view (1) that these two substances may act through some final common mechanism. It is well known (1) that these drugs are closely similar pharmacologically and in this study no essential difference in hemodynamic activity has been seen. Hence, in discussing the site of action of these drugs, ephedrine and adrenin will be considered together.

It is well known (1) that the effect of adrenin upon the vascular beds throughout the body varies from site to site; e.g., dilatation of the vessels of skeletal muscle and constriction of the arterioles of the skin and kidney. Since the over-all circula- tory response reflects the summated responses of all of the vascular beds, it is apparent that the predominance of any one bed in an individual would influence the direction of the hemodynamic change in that person. Thus, a subject with a relatively large skin circulation, as in a person of poor muscular development and large surface area, the constriction of these vessels in response to adrenin could conceivably so dominate the hemodynamic picture that the over-all peripheral resistance would be increased and the diastolic pressure elevated. Of course, the actual situation is much more complex and a simple relation between surface area or body weight and the action of the drug could not be expected to obtain, especially when the relative parts played by the splanchnic and organ circuits are considered. On the whole, the vasodilator effects of adrenin have dominated the hemodynamic picture observed in the present 
series, and in most instances, the peripheral vascular resistance has remained unchanged or has decreased. This response was also seen with ephedrine. In every instance in which an elevation of resistance occurred, a marked rise in arterial pressure with an elevated diastolic pressure was seen. Even in these instances, however, the increase in resistance was relatively small. The over-all pressor response, then, is largely a function of the increased cardiac output rather than a function of the peripheral activity of these substances. In addition, there is evidence that these drugs act directly upon the central arteries. In every instance of pressure increase, the pulse pressure widened. This increase in pulse pressure was not always immediately associated with an increase in the cardiac output and was even associated with a fall in the stroke volume. This phenomenon indicates either a decrease in the distensibility of the central arteries, or a marked reduction in the "Windkessel" volume, with a corresponding increase in the stroke volume: aortic capacity ratio (14). Neither of these two possibilities can be excluded at the present time. The increase in cardiac output is associated with an increase in auricular pressure which appears with the blood pressure elevation and accompanies it. It is not unlikely that the increase in auricular pressure reflects the discharge of the blood depots and an increase in the circulating blood volume. However, the relative roles of increased venous tone and of increased skeletal muscular tone in increasing return of blood to the heart and thus right intra-auricular pressure, cannot now be evaluated. The increase of cardiac output obviates, in all probability, the action of backward transmission of pressure across the pulmonary bed. In one instance, a marked reduction of the heart rate was observed at the height of the pressor effect. This bradycardia may be interpreted as a vagal effect of the pressure elevation (1).

The hemodynamic and renal effects of paredrinol are strikingly similar to those produced in man by angiotonin (15). This substance also increases arterial pressure and decreases stroke volume and cardiac output, despite an elevation of venous and right auricular pressure. The fact that the rise in arterial pressure is coincidental with the rise in calculated peripheral vascular re- sistance indicates that the peripheral vascular bed is the primary site of action of paredrinol. The failure of the heart to increase its output and stroke volume in the face of increased filling pressure indicates increased resistance to filling or increased cardiac tone. This is also true of angiotonin. It cannot be said with certainty, however, that the elevation of right auricular pressure is due to the decrease in cardiac output, for an increase in venous tone may play an important role in causing the elevation of auricular and venous pressures. Since Altschule et al. (16) have shown that paredrine does not change vital capacity, it may be inferred that paredrinol behaves similarly. Hence, it does not seem likely that the transpulmonary transmission of pressure could be a factor in raising right auricular pressure. Here, as with adrenin and ephedrine, increased skeletal muscle tone may play a part in speeding the return of blood to the heart.

The renal function studies reveal that all of these substances have a similar effect upon the kidney. Accepting Smith's hypothesis that filtration equilibrium obtains at the glomerulus (17), then the reduction in renal plasma flow, associated with an increased filtration fraction, implies constriction of the efferent arterioles.

\section{SUMMARY}

A study of systemic and renal circulatory changes in 31 normal subjects, during the action of adrenin, ephedrine, and paredrinol, has been reported. Cardiac output has been measured by the ballistocardiograph, arterial pressure with the Hamilton manometer, and right intra-auricular pressure, following catheterization of the right heart, with a saline manometer. Renal plasma flow was determined as diodrast clearance, glomerular filtration rate as mannitol or inulin clearance, and the filtration fraction as the mannitol/ diodrast ratio.

Adrenin and ephedrine were found to display similar activity. Evidence was adduced to support the view that the vasodilator action of these substances dominated the hemodynamic picture with an increase in cardiac output, associated with increased intra-auricular pressure, producing the pressor effects. Increased pulse pressure, without corresponding increases in stroke volume or 
cardiac output, indicated a direct action of these drugs upon the central arteries.

Paredrinol has proved to be a predominantly vasconstrictor drug with its primary site of action in the periphery. Peripheral resistance and blood pressure rose while cardiac output declined in the face of increased right auricular pressure. It was inferred that paredrinol increased cardiac tone.

All the substances studied produced identical renal effects. Renal plasma flow decreased without significant change in the glomerular filtration rate and the filtration fraction increased, indicating efferent arteriolar vasconstriction.

We wish to acknowledge our debt to Mr. Ray Houde for assistance in computations, to Miss Claire Lawler and Miss Martha Barrett for technical assistance, and to Nurse Agatha Evaskitis.

\section{BIBLIOGRAPHY}

1. Goodman, L., and Gilman, A., The Pharmacological Basis of Therapeutics. The Macmillan Co., New York, 1941.

2. Cournand, A., Ranges, H. A., and Riley, R. L., Comparison of results of the normal ballistocardiogram and a direct Fick method in measuring the cardiac output in man. J. Clin. Invest., 1942, 21, 287.

3. Starr, I., Rawson, A. J., Schroeder, H. A., and Joseph, N. R., Studies on the estimation of cardiac output in man, and of abnormalities in cardiac function, from the heart's recoil and the blood's impacts; the ballistocardiogram. Am. J. Physiol., 1939, 127, 1.

4. Starr, I., and Schroeder, H. A., Ballistocardiogram. II. Normal standards, abnormalities commonly found in diseases of the heart and circulation, and their significance. J. Clin. Invest., 1940, 19, 437.

5. Hamilton, W. F., Brewer, G., and Brotman, I., Pressure pulse contours in the intact animal. I. Analytical description of a new high-frequency hypodermic manometer with illustrative curves of simultaneous arterial and intracardiac pressures. Am. J. Physiol., 1934, 107, 427.
6. Apéria, A., Hemodynamical studies. Skandinav. Arch. f. Physiol., 1940, Suppl. 16, 83, 1.

7. Cournand, A., and Ranges, H. A., Catheterization of the right auricle in man. Proc. Soc. Exper. Biol. and Med., 1941, 46, 462.

8. Lyons, R. H., Kennedy, J. A., and Burwell, C. S., The measurement of venous pressure by the direct method. Am. Heart J., 1938, 16, 675.

9. Richards, D. W., Jr., et al., Pressure of blood in the right auricle, in animals and in man: under normal conditions and in right heart failure. Am. J. Physiol., 1942, 136, 115.

10. Smith, H. W., Goldring, W., and Chasis, H., The measurement of the tubular excretory mass, effective blood flow and filtration rate in the normal human kidney. J. Clin. Invest., 1938, 17, 263.

11. Smith, W. W., Finkelstein, N., and Smith, H. W., Renal excretion of hexitols (sorbitol, mannitol, and dulcitol) and their derivatives (sorbitan, isomannide, and sorbide) and of endogenous creatininelike chromogen in dog and man. J. Biol. Chem., 1940, 135, 231.

12. Böger, A., and Wezler, K., Die Bestimmung des arteriellen Gesamtwiderstandes am Menschen. Arch. f. exper. Path. u. Pharmakol., 1937, 186, 43.

13. Chasis, H., Ranges, H. A., Goldring, W., and Smith, H. W., The control of renal blood flow and glomerular filtration in normal man. J. Clin. Invest., 1938, 17, 683.

14. Wiggers, C. J., The influence of vascular factors on mean pressure, pulse pressure and phasic peripheral flow. Am. J. Physiol., 1938, 123, 644.

15. Bradley, S. E., and Parker, B., The hemodynamic effects of angiotonin in normal man. J. Clin. Invest., 1941, 20, 715.

16. Altschule, M. D., and Iglauer, A., The effect of benzedrine ( $\beta$-phenylisopropylamine sulphate) and paredrine ( $\rho$-hydroxy- $a$-methylphenylethylamine hydrobromide) on the circulation, metabolism and respiration in normal man. J. Clin. Invest., 1940, $19,497$.

17. Smith, H. W., Chasis, H., Goldring, W., and Ranges, H. A., Glomerular dynamics in the normal human kidney. J. Clin. Invest., 1940, 19, 751. 